From: Human Rights Afghanistan <hrafghanistan@undpafg.org.pk>

Sent: $\quad$ Sunday, May 13, 2001 9:02 AM

Attach: hrafghanistan.vcf

Subject: SUMMARY OF THE FIFTY-SEVENTH SESSION OF THE COMMISSION ON HUMAN

\title{
THE FIFTY-SEVENTH SESSION OF THE COMMISSION ON HUMAN RIGHTS
}

(19 March - 27 April 2001)

Background paper

Ambassador Leandro Despouy, a former victim of human rights violations in his own country, Argentina, who was later a member and Special Rapporteur of the Sub-Commission, was elected Chairperson of the Commission. In his opening statement he referred to human rights as the most important cultural revolution of the 20th century and to the Universal Declaration as one of the main legacies of the millennium. He noted the importance of harmonizing the work of various human rights organs and the special procedures mechanisms of the Commission, and the need to support them financially. The Chair underlined the need for a specific instrument dealing with enforced disappearances, the special role played by NGOs and the importance of the recent appointment of a Special Representative of the Secretary-General on human rights defenders. He concluded his statement with an evaluation of the positive developments which had occurred in recent years in the field of human rights in the Mercosur countries.

Ambassador Najat Al-Hajjaji (Libyan Arab Jamahiriya), Ambassador Anda Filip (Romania) and Ambassador Álvaro de Mendonça e Moura (Portugal) were elected Vice-Chairpersons and Mr. Imtiaz Hussain (Pakistan) was elected Rapporteur. The regional coordinators constituting the Expanded Bureau were the representatives of India, Kenya, Latvia, Mexico and the United Kingdom.

During the total meeting time of 219 hours, over 1,300 statements were made; over 3,600 individuals attended the session and close to 8,000 pages were issued as official documentation. A total of 82 resolutions ( 50 by consensus, 32 by roll-call vote) and 19 decisions ( 18 without a vote and 1 by roll-call vote) were adopted and 3 Chairperson's statements (on Colombia, East Timor and Haiti) were made.

Three States members of the United Nations participated for the first time as members of the Commission: Saudi Arabia, Thailand and Viet Nam.

The Commission heard statements by 69 dignitaries, including the Secretary-General and five Heads of State: President Joseph Kabila of the Democratic Republic of the Congo; President Jacques Chirac of France; President Boris Trajkovski of the former Yugoslav Republic of 
Macedonia; President Moritz Leuenberger of Switzerland and President Vojislav Kostunica of the Federal Republic of Yugoslavia. This was the largest number of Heads of State to address the Commission, and the total number of dignitaries equalled the record set in 1998, the year of the 50th anniversary of the Universal Declaration.

The large number of dignitaries seems to confirm that member States consider it worthwhile for senior political figures to convey their concerns to the international community through the Commission on Human Rights and make public their Governments' positions on a wide range of human rights issues, as well as their intentions to submit or support draft proposals.

The Commission is also seen as the forum from which major commitments should

be announced. The Minister for Foreign Affairs of Mexico said: "I have come to this forum with the mandate of my Government and of the Mexican people to express Mexico's new commitment to respecting and, along with the international community, ensuring the respect for human rights throughout the world. The Government of Mexico has chosen this forum to put before the world community a series of actions which attest to a vital change in Mexican policy regarding these transcendental values".

\section{Context of the fifty-seventh session}

The fifty-seventh session of the Commission took place against the background of: last year's Millenium Assembly; the fifth special session of the Commission on the situation in the Middle East held in October 2000; the third United Nations Conference on the Least Developed Countries to be held in Belgium in May 2001; the on-going preparatory work for the General Assembly special session on AIDS in June 2001; four months before the World Conference against Racism; and a few months ahead of the General Assembly Special Session on Children (19-21 September 2001). The Durban Conference received special attention from most participants and became one of the main themes of this Commission.

The Secretary-General in his statement expressed his conviction that previous world conferences had given the people of the world a series of dynamic blueprints for progress on key issues such as the environment, the advancement of women and, not least, human rights. "The World Conference against Racism has similar potential to reach deeply into the lives of people, and give them both help and hope". "Governments are the main violators of human rights, and bear the main responsibility for promoting and protecting them. For that, we must look to the Conference Declaration and Programme of Action". At the same time, "we need a document that inspires all people, not just Governments, to do their part". 
The High Commissioner also referred to the World Conference against Racism as the main priority of the Commission and her Office in the year 2001, and her report focused on this major event. She noted that the main issues to be addressed by the Conference had been identified. She expressed confidence that even sensitive issues such as slavery and the matter of compensation could be dealt with in language acceptable to all. She highlighted the specific impact of racism on women and children: "Too many children in the world are deprived of basic education, health care, food, or adequate housing simply because they do not belong to the 'right' race, ethnicity, nationality or colour".

In this context, the main value of the Special debate on tolerance and respect was the opportunity offered to explore action-oriented ways and means of promoting the principles of tolerance and respect at the World Conference.

\section{Special debate on tolerance and respect - 26 March 2001}

This year the Commission devoted almost three entire meetings to the special debate.

Archbishop Desmond Tutu (South Africa), Senator Aden Ridgeway (Australia) and Sheikh Shaib Ben Sheikh (Algeria) addressed the Commission during the morning session, focusing, respectively, on the issues of reconciliation, social exclusion and religion. In the afternoon Dr. Nafis Sadik (former Executive Director of the United Nations Population Fund), Ms. Cecilia Braslavsky (Director of the International Education Office of UNESCO) and Mr. Dominique Peccoud (Special Adviser to the Director-General of ILO for External Relations and Partnerships) addressed the Commission, focusing, respectively, on the issues of gender, education and migration. The panelists were given the opportunity to make concluding remarks as was the Chairperson.

A total of 17 governmental delegations and 12 NGOs (some speaking on behalf of groups of others) participated in the debate.

The Chairperson, in his concluding remarks, which were subsequently circulated in document E/CN.4/2001/162, underlined the extremely touching message of solidarity, interdependence and complementarity of all human beings delivered by Archbishop Tutu, as well as the assertion that apartheid could not have been defeated without the continued support of the international community and that other difficult issues could also be solved in the same way. Referring to the statement made by Senator Ridgeway, the only indigenous member of the Australian Federal Parliament, the Chairperson stressed the importance of respecting those rights that are specific to indigenous people, in particular the rights to land, culture and to heritage. The Chairperson quoted the words of Sheik Shaib Ben Sheik, Mufti of Marseilles, who appealed to religious leaders, not to define principles rigidly; "A religion cannot define rules for future 
generations... What would represent progress for one generation might become regress for future generations". The Chairperson summarized the intervention of Dr. Sadik recalling that, on the one hand, women suffer disproportionately the effects of discrimination - and this is still largely the case all over the world - and, on the other hand, the fact that it is now possible to discuss delicate issues openly is evidence of progress. The Chairperson referred to Mr. Peccoud's convincing arguments that migrants enrich societies and, whether they are legal or not, their basic human rights should be respected. With regard to the last panelist, he stressed that Ms. Braslavsky had repeatedly underlined the importance of the "quality" of education in promoting tolerance and respect.

\section{The Middle East}

Three important documents were considered this year by the Commission concerning the situation in the Middle East: the report of the Special Rapporteur, the report of the commission of inquiry established pursuant to Commission resolution $\mathrm{S}-5 / 1$, and the report of the High Commissioner on her mission to the region.

Mr. Giorgio Giacomelli, the Special Rapporteur, reiterated the recommendations contained in his report to the fifth special session and officially announced that he had submitted his resignation.

The High Commissioner expressed concern at the bleak human rights situation prevailing in the occupied Palestinian territories. She referred to the deaths of children and young people on both sides as tragic and quoted the recent statement made by the Secretary-General in Oman. While acknowledging the insecurity felt by many Israelis, the High Commissioner cited the expansion of settlements, the destruction of property and the devastating economic effects of the restrictions imposed on the Palestinians as amongst the key factors underlying the current violence and called for a reduction of the Israeli presence in the Palestinian territories.

The Chairperson of the commission of inquiry reported on the main findings contained in the report. The Israeli Defence Forces were considered to be guilty of excessive use of force. The role of settlements in fuelling the conflict was underlined as well as the fact that they constituted a violation of the Fourth Geneva Convention. The economic hardships imposed by restrictions on the movement of people and goods were emphasized. Reference was made to the need for the deployment of an international presence in the region, the need for the High Contracting Parties to the Fourth Geneva Convention to reconvene their adjourned Conference and that 'steps be taken to ensure Israeli's compliance with its obligations. Mention was also made of the role that the European Union could play in the peace process. 
Resolution 2001/7, entitled " Question of the violation of human rights in

the occupied Arab territories, including Palestine", was adopted by a roll-call vote of 28 in favour, 2 against and 22 abstentions. This resolution was the subject of intense negotiations between States members of the Arab League and the European Union. In the vote, the States members of the European Union abstained. The Commission expressed its deep concern at the failure of the Government of Israel to cooperate with the special procedures mechanisms. The mandate of the commission of inquiry was not renewed; the new Special Rapporteur (to be appointed), acting as a monitoring mechanism, has been requested to follow up on the implementation of the recommendations of the commission of inquiry and on those contained in the report of the High Commissioner.

Country situations and the 1503 procedure

Resolutions were adopted concerning the situations of human rights in Afghanistan (without a vote); Burundi (without a vote); the Democratic Republic of the Congo (without a vote); Cuba (22-20-10) ; Equatorial Guinea (without a vote); the Republic of Chechnya of the Russian Federation (22-12-19); the Islamic Republic of Iran (21-17-15); Iraq (30-3-19); Myanmar (without a vote); Rwanda (28-16-9); Sierra Leone (without a vote); Sudan (28-0-25); and the human rights situation in parts of south-eastern Europe (41-0-11).

The mandates of the respective country special rapporteurs were all renewed, with the exception of Rwanda (res. 2001/23 puts an end to the mandate of the Special Representative) and parts of south-eastern Europe (res. 2001/12 puts an end to the mandate of the Special Rapporteur for the former Yugoslavia and requests approval for the appointment of a special representative for one year with a mandate to examine the situation of human rights in Bosnia and Herzegovina and the Federal Republic of Yugoslavia, thus ending the supervisory mandate for Croatia).

The Special Representative of the Secretary-General for East Timor and Head of the United Nations Transitional Administration in East Timor (UNTAET) reported to the Commission on 5 April 2001 on the progress achieved in the reconstruction of the territory and in the functioning of a civilian administration. UNTAET was helping to build a new nation, having in view the independence of the country in early 2002.

A motion that the Commission take no action on a draft resolution on the situation of human rights in China was carried by 23 votes in favour, 17 against and 12 abstentions.

Four countries were considered this year under ECOSOC resolutions 1503 and 2000/3, namely: Republic of the Congo, Maldives, Togo and Uganda. The Commission decided to discontinue consideration of the Republic of 
Congo, Maldives and Uganda; Togo remains under review under the 1503 procedure. The Commission had before it, this year, under public procedure, the report of the International Commission of Inquiry for Togo which had been transmitted to the Secretary-General of the United Nations and the Secretary-General of the Organization of African Unity in December 2000 (doc. E/CN.4/2001/134 - E/CN.4/Sub.2/2001/3 and Add. $1-3)$. No decision in public procedure was taken with regard to this report.

Confidentially, the Commission took the decision to postpone consideration until its next session of the question of the interaction of the 1503 procedure with the procedure of the Commission on the Status of Women.

New mandates requiring early action by ECOSOC

To ensure prompt implementation of special procedures mandates, ECOSOC had agreed, in its decision 1999/256, to include in its organizational session in May consideration of new proposals regarding special procedures mandates adopted by the Commission.

This year the Commission adopted the following proposals regarding new special procedures mandates:

(a) In resolution 2001/12, as mentioned earlier, the Commission decided to appoint a special representative to examine the situation of human rights in Bosnia and Herzegovina and the Federal Republic of Yugoslavia (para.40);

(b) In resolution 2001/30, entitled "Question of the realization in all countries of the economic, social and cultural rights contained in the Universal Declaration of Human Rights and in the International Covenant on Economic, Social and Cultural Rights, and study of special problems which the developing countries face in their efforts to achieve these human rights", the Commission decided to appoint an independent expert to examine the question of a draft optional protocol to the International Covenant on Economic, Social and Cultural Rights (para. 8 (c)). The independent expert is requested to submit a report to the Commission at its fifty-eighth session with a view to its consideration of possible follow-up and future actions, including the establishment of an open-ended working group of the Commission to examine the question of a draft optional protocol to the International Covenant on Economic, Social and Cultural Rights;

(c) In resolution 2001/46, entitled "Question of enforced or involuntary disappearances", the Commission decided to appoint an independent expert to examine the existing international criminal and human rights framework for the protection of persons from enforced or involuntary disappearance (para. 11) and to establish at its fifty-eighth session an 
inter-sessional open-ended working group with the mandate to elaborate a draft legally binding normative instrument for the protection of all persons from enforced disappearance (para. 12);

(d) In resolution 2001/57, entitled "Human rights and indigenous issues", the Commission decided to appoint a special rapporteur on the situation of human rights and fundamental freedoms of indigenous people (para. 1) with the following main functions: to gather, request, receive and exchange information and communications from all relevant sources; to formulate recommendations and proposals on appropriate measures and activities to prevent and remedy violations of the human rights and fundamental freedoms of indigenous people; and to work in close relation with other special rapporteurs, special representatives, working groups and independent experts of the Commission on Human Rights and of the Sub-Commission on the Promotion and Protection of Human Rights.

\section{Innovative or new resolutions/decisions}

For the first time the Commission adopted, without a vote, a separate resolution (2001/29) on the right to education, renewing the mandate of the Special Rapporteur for a period of three years and inviting her to intensify efforts to identify ways and means to overcome obstacles and difficulties in the realization of that right.

The Commission adopted, without a vote, resolution 2001/33 entitled "Access to medication in the context of pandemics such as HIV/AIDS", calling upon States to pursue policies which would promote the availability in sufficient quantities of pharmaceuticals and medical technologies, the accessibility to all without discrimination of such pharmaceuticals or medical technologies and the assurance that pharmaceuticals or medical technologies are scientifically and medically appropriate and of good quality. The Secretary-General is requested to solicit comments from Governments, United Nations organs, programmes and specialized agencies and international and non-governmental organizations on the steps they have taken to promote and implement, where applicable, the resolution, as well as to report thereon to the Commission at its fifty-eighth session.

By its decision 2001/111 entitled "Science and the environment", the Commission, bearing in mind the forthcoming Rio+10 Conference, decided, without a vote, to invite the High Commissioner for Human Rights and the Executive Director of the United Nations Environment Programme to consider the organization of a joint seminar, to be funded from voluntary contributions, to review and assess progress achieved since the United Nations Conference on Environment and Development in promoting and protecting humán rights in relation to environmental questions and in the framework of Agenda 21.

On the issue of human rights and bioethics, a biennial topic, the Commission this year (res. 2001/71, adopted without a vote) invited 
the Secretary-General to consider establishing a working group of independent experts from, inter alia, UNESCO, WHO and WIPO, which would reflect, in particular, on the possible follow-up to the Universal

Declaration on the Human Genome and Human Rights (para. 4), and again requested the Sub-Commission to consider what contribution it could make on the subject and to report to the Commission at its fifty-ninth session (para.8).

A new resolution entitled "Protection of migrants and their families"(res. 2001/56) was adopted this year, without a vote. It encourages States of origin and of destination of migrants to consider the adoption of bilateral or regional strategies aimed at protecting the human rights of migrants and their families, as a matter of priority and in conformity with the appropriate legislation, and to effectively combat international trafficking and smuggling of migrants and to protect migrants and their families from exploitation and intimidation by traffickers, smugglers and criminal organizations (para.6).

The traditional resolution "Towards a culture of peace" was replaced this year by resolution 2001/69 entitled "Promotion of the right of peoples to peace" adopted by a roll-call vote of 29 in favour, 16 against and 7 abstentions.

A new resolution $(2001 / 76)$ on "Equitable geographical distribution of the membership of the human rights treaty bodies" was adopted by a roll-call vote of 35 in favour, 15 against and 2 abstentions.

A new resolution on "Human rights and international solidarity" (res. 2001/73) was adopted by a roll-call vote of 36 in favour, 16 against with no abstentions.

\section{Debate on thematic resolutions}

The traditional resolution on human rights and thematic procedures, adopted in previous years without a vote, was this year postponed to next year (the text is contained in

L. 91) together with amendments (L.104) submitted by the delegation of Cuba. All thematic mandates that were due for renewal were renewed; however, more were voted on than in the past.

The mandate of the Special Rapporteur on mercenaries was renewed for three years

(res.2001/3, adopted by a roll-call vote of 35 votes to 11 , with 6 abstentions). The mandate of the Special Rapporteur remains the same as in the past, notwithstanding the recommendations of the expert meeting which took place in January 2001 (E/CN.4/2001/18) calling for the inclusion of new forms of mercenary activity and of clearer legal definition of "mercenary". Those who voted against the resolution felt that the issue of mercenaries should be rather dealt with by the Sixth 


\section{Committee of the General Assembly.}

The mandate of the Special Rapporteur on toxic wastes was renewed for three years (res. 2001/35). The mandate remains very much the same as in the past. No mention is made of the possible change in the title of the mandate as recommended by the Working Group on the review of mechanisms ( E/CN.4/2000/112), to "human rights and the environment". This resolution was adopted by a roll-call vote of 38 votes to 15 . Those voting against considered that this issue should be dealt with in another forum.

The mandate of the Special Rapporteur on the question of torture has been extended for a period of three years. Resolution 2001/62, following extensive consultations, postponements, amendments and separate votes on some paragraphs was finally adopted without a vote.

The mandate of the Special Rapporteur on religious freedom was extended for three years without a vote (res. 2001/42).

The resolution on "The right to freedom of opinion and expression" usually adopted without a vote, was adopted this year by a roll-call vote of 44 to none, with 8 abstentions. (res. 2001/47).

For the first time, many States insisted during their interventions that they had extended a standing invitation to all special procedures of the Commission. In this context, the permanent invitation extended by the Government of Mexico to mandate-holders of international human rights mechanisms to visit the country was highly praised by several delegations, including NGOs. A total of 33 countries have now extended such permanent invitations, including all the members of the European Union.

The Chairperson of the Commission made an appeal to delegations on 12 April 2001 concerning the need to respect the integrity of all those participating in the work of the Commission. This appeal was made in the context of remarks that had been made with regard to certain mandate-holders. The High Commissioner in her closing statement expressed deep concern at criticisms made during the session which had reached the level of personal attacks against a number of special rapporteurs. The Chairperson spoke also at the closing ceremony of the need to continue to support the Commission's special procedures.

The right to development and economic, social and cultural rights.

Under agenda item 7 (Right to development) the Commission adopted resolution 2001/9, entitled "The right to development", by a roll-call vote of 48 in favour, 2 against (Japan, USA) and 3 abstentions. Before voting on the whole resolution, Canada requested a separate vote on operative paragraphs 10,21 and 22. Paragraph 21, in particular, 
recognizes that it is necessary to enhance efforts to consider and evaluate the impact of international economic and financial issues on the enjoyment of human rights, such as international trade issues, access to technology, good governance and equity at the international level and debt burden. The mandate of the working group was extended for one year, and the mandate of the independent expert for three years.

Under agenda item 10 (Economic, social and cultural rights) resolution 2001/27 entitled "Effects of structural adjustment policies and foreign debt on the full enjoyment of all human rights, particularly economic, social and cultural rights", adopted by a roll-call vote of 31 in favour, 15 against and 7 abstentions, requests ECOSOC to authorize the working group on structural adjustment to meet for two weeks prior to the fifty-eight session of the Commission and to report to the Commission. The independent expert on the subject is asked to report to the working group and to assist the group in the fulfilment of its mandate.

After a separate vote on paragraph 5 of res. 2001/34 entitled "Women's equal ownership of, access to and control over land and the equal rights to own property and to adequate housing" which refers, inter alia, to "the right to adequate housing" for women, the resolution was adopted, as had been the case last year, without a vote.

\section{Democracy and good governance}

A number of resolutions under different agenda items (11 and 17) were adopted this year highlighting different approaches to democracy and governance issues.

-Resolution 2001/36 entitled "Strengthening of popular participation, equity, social justice and non-discrimination as essential foundations of democracy", adopted by a roll-call vote of 28 in favour, 4 against and 21 abstentions;

-Resolution 2001/41 entitled "Continuing dialogue on measures to promote and consolidate democracy" adopted by a roll-call vote of 44 in favour, none against and 9 abstentions;

-Resolution 2001/43 entitled "The incompatibility between democracy and racism", adopted without a vote;

- Resolution 2001/72 entitled "The role of good governance in the promotion of human rights", adopted without a vote.

Relations with the Sub-Commission

While the Commission has given a number of guidelines to the 
Sub-Commission (res. 2001/60), it approved only 5 out of $14 \mathrm{draft}$ decisions proposed for adoption by the Sub-Commission. All others were either rejected or returned to the Sub-Commission for "rethinking".

CHR 57th: more of everything

The fifty-seventh session was characterised by more plenary meetings (80 this year, compared to 69 last year); more statements during the general debates, more points of order and more rights of reply; more interventions while taking action on proposals; more resolutions/decisions than ever before (a total of 108 "L" documents submitted and 101 resolutions/decisions adopted) and, overall, more voting (notably by roll-call); more amendments and sub-amendments; more procedural manoeuvres. Also - and this is positive - more group statements this year, not only from the European Union, but also, notably, from GRULAC, the Mercosur countries, the Central American countries, the Asian Group, the African Group, and from States members of the Organization of the Islamic Conference. However, this tendency towards joint statements by governments has not yet had a substantial impact on reducing the number of statements. More participants, in particular women participants $(1,427$ out of 3,663$)$, made it ever-more evident that conference room XVII at times is too small. More parallel activities took place: 361 held by Governments; 153 organized by NGOs; 59 organized by $\mathrm{OHCHR}$ and DPI, including 24 briefings by special rapporteurs; 146 meetings of regional groups and 4 consultations of the Bureau with NGOs.

In the words of the Chairperson, during his concluding remarks:"More of everything".

This over-expansion threatens the effectiveness of the Commission. At the end of the fifty-seventh session a new awareness seemed to have emerged that this trend cannot continue. There is a risk of fractures. There is a need to return to consensus on important issues. Also, as underlined by the Chairperson in his closing statement, it is necessary to improve the methods of work of the Commission "with urgency, creativeness, and a good dose of realism".

Inter-sessional activities of the Expanded Bureau

Without having been given a formal mandate, the Expanded Bureau of the Commission, under the able leadership of the Chairperson, seems to be committed to carry out a number of consultations and to address the following issues during the inter-sessional period:

-Main rules and practices followed by the Commission in the organization of its work and the conduct of business;

-Time management issues;

-Documentation issues; 
-Interactive dialogue with special procedures mandate-holders;

-Relations with ECOSOC and the other functional commissions, as well as with the NGO Committee;

-Consultations with treaty bodies;

-Consultations with NGOs;

-Consultations with specialized agencies, United Nations Departments and programmes;

-Preparation of the informal one-day meeting of the Commission on 25

September 2001;

-Relations with the Sub-Commission on the Promotion and Protection of Human Rights; and

-Follow-up to the World Conference against Racism.

Resources

The Commission, in its last decision adopted this year (decision 2001/117), associated itself with the strong message delivered by numerous dignitaries at this year's session that adequate budgetary resources are a necessary prerequisite if the Office of the High Commissioner is to fulfill its responsibilities and the mandates established by Member States.

Dates of the fifty-eighth session of the Commission

The 58th session of the Commission will take place from 18 March to 26 April 2002. 
Page 13 of 13

MFC

Geneva, 2 May 2001 